\title{
Estimates of food and macronutrient intake in a random sample of Northern Ireland adolescents
}

\author{
BY J. J. STRAIN ${ }^{1}$, P. J. ROBSON'1, M. B. E. LIVINGSTONE', E. D. PRIMROSE ${ }^{2}$, \\ J. M. SAVAGE ${ }^{2}$, G. W. CRAN ${ }^{3}$ AND C. A. G. BOREHAM ${ }^{4}$ \\ ${ }^{1}$ Human Nutrition Research Group, University of Ulster, Coleraine BT52 ISA, \\ ${ }^{2}$ Department of Statistics and Operational Research, ${ }^{3}$ Department of Child Health, and \\ ${ }^{4}$ Department of Physical and Health Education, The Queen's University of Belfast, BT7 1NN
}

(Received 2 July 1993 - Revised 1 December 1993 - Accepted 14 January 1994)

\begin{abstract}
Estimates of food consumption and macronutrient intake were obtained from a randomly selected population sample ( $2 \%$ ) of 1015 adolescents aged 12 and 15 years in Northern Ireland during the 1990/1991 school year. Dietary intake was assessed by diet history with photographic album to estimate portion size. Reported median energy intakes were 11.0 and $13.1 \mathrm{MJ} / \mathrm{d}$ for boys aged 12 and 15 years respectively and $9 \cdot 2$ and $9 \cdot 1 \mathrm{MJ} / \mathrm{d}$ for girls of these ages. Protein, carbohydrate and total sugars intakes as a percentage of total energy varied little between the age and sex groups and were approximately 11, 49 and $20 \%$ respectively of daily total energy intakes. Median dietary fibre intakes were approximately 20 and $24 \mathrm{~g} / \mathrm{d}$ for boys aged 12 and 15 years respectively and 18 and $19 \mathrm{~g} / \mathrm{d}$ for girls of these ages. Major food sources of energy (as a percentage of total energy intakes) were bread and cereals (15-18\%), cakes and biscuits (12-14\%), chips and crisps (13-14\%), dairy products (9-11\%), meat and meat products $(9-11 \%)$ and confectionery $(9 \%)$. Fruit and vegetable intakes were low at about $2.5 \%$ and $1.5 \%$ respectively of total energy intakes. Median fat intakes were high at $39 \%$ of total daily energy intakes. Major food sources of fat as a percentage of total fat intakes were from the food groupings: chips and crisps (16-19\%), meat and meat products (14-17\%), fats and oils (14-16\%), cakes and biscuits (13-16\%) and dairy products (12-15\%). Median intakes of saturated fatty acids were also high at approximately $15 \%$ of daily total energy intake while intakes of monounsaturated fatty acids averaged $12 \%$ of daily total energy intake. Median polyunsaturated fatty acid (PUFA) intakes were low, comprising 5.2 and $5.5 \%$ of daily total energy intake for boys aged 12 and 15 years respectively and were lower than the PUFA intakes (5.9 and 6.3\% of daily total energy intake) for girls of these ages. About $1.3 \%$ for boys and $1.4 \%$ for girls of daily total energy intake was in the form of $n-3$ PUFA. Ca and Mg intakes were adequate for both sexes. Based on these results, some concern about the dietary habits and related health consequences in Northern Ireland adolescents appears justified.
\end{abstract}

Northern Ireland adolescents: Diet history: Macronutrients: Food consumption

Atherosclerosis is increasingly being recognized as, in part, a nutritionally-related problem which develops in childhood and adolescence (Prasad \& Chandra, 1991). Death rates from ischaemic heart disease (IHD) in Northern Ireland remain among the highest in the world (Uemura \& Pisa, 1988) and recently published data suggest that the high incidence of IHD in the adult population is reflected by the risk status of Northern Ireland schoolchildren (Boreham et al. 1993).

Adolescence is a time of significant change of lifestyle and food habits that affect both nutrient intake and requirements. Although data on dietary intake are available for a random sample of the Northern Ireland population aged 16-64 years (Strain et al. 1990), very little information is available for the younger age groups. The aim of the present study, 
therefore, was to estimate food consumption and nutrient intake in a random sample of Northern Ireland adolescents aged 12 and 15 years.

\section{METHODS}

\section{Subjects}

The sampling procedure was designed to select a sample of approximately 250 subjects from each of the following four groups: boys aged 12 and 15 years, and girls aged 12 and 15 years. The procedure took account of geographical spread and the different categories of schools in Northern Ireland. In order to allow for non-response and drop-outs the target numbers were increased by approximately $20 \%$. A total of 1015 subjects were tested giving a response rate of $78 \%$ and accounting for a $2 \%$ random sample of each of the two age populations in Northern Ireland. Further information on sampling procedure and reasons for non-response has been published elsewhere (Boreham et al. 1993). The dietary information reported here was collected as part of a larger study to establish the nature and extent of factors associated with coronary risk in Northern Ireland schoolchildren. Information on these subjects is also available for height, weight, body composition, pubertal status, blood pressure, blood cholesterol, activity patterns, cardiorespiratory fitness, smoking status and family history of cardiovascular disease (Boreham et al. 1993). Prior ethical approval for the study was secured from the Queen's University of Belfast Ethical Committee and written informed consent obtained from the parent or guardian of participating subjects.

\section{Diet history methodology}

The diet history method (Van Stavern et al. 1985) was used to record the usual weekly meal and snack consumption of the subjects. Estimates of habitual food intake were obtained by three trained fieldworkers using an open-ended interview and an album of known portion weights of foods (Lee \& Cunningham, 1990). The number of interviews conducted by each fieldworker was approximately equal for each age-sex group. The following quality control measures were undertaken. (a) Before fieldwork each of the three fieldworkers completed an extensive training in diet history protocol. (b) Efforts were made to contact school canteen supervisors in order to obtain lists of menus, recipes and information on food preparation techniques. The menus were used during the interview for prompting when a subject indicated that he/she took school lunches. (c) School cafeterias and tuck shops were visited in order to inspect available products. (d) Certain items such as recipe dishes and confectionery, the nutrient content of which was unknown, were purchased and weighed, and in some cases manufacturers were contacted. (e) Measuring spoons were used during the dietary interview to assist in estimating portion sizes.

The interview with each subject took place in the schools concerned. Each interview lasted about $1 \mathrm{~h}$, the length of time depending on the complexity and/or stability of eating patterns. The fieldworker emphasized that the required information concerned usual dietary habits and not necessarily foods consumed in the previous week. The initial part of the interview involved establishing the content of meals and snacks for a typical week. Weekdays and weekend days were investigated separately. In general subjects ate defined meals of breakfast, lunch and dinner. Snacks were, therefore, defined as all foods and drinks consumed between meals. Foods eaten less than once a fortnight were not recorded. If the subject was uncertain of specific details, he/she was instructed to inquire at home and return with the relevant information. The second part of the interview was concerned with the quantification of food intake. Portion sizes were estimated with the aid of an album, which contained 172 photographs ( 154 of food portions of known weights, nine of packets 
of margarine, three of cartons of milk and six of crockery). The respondent reported the fraction/multiple of the portion normally consumed (as opposed to the amount served). Where no photograph was available for comparison, use was made of standard household measures and average portion sizes (Crawley, 1988) to quantify the results. Food intakes recorded in the diet histories were coded using McCance and Widdowson's food tables (Paul \& Southgate, 1978; Paul et al. 1980) with additional codes from a computerized database described by McClean et al. (1990) and from Comp-Eat (Lifeline Nutritional Services Ltd., London). The enclosed data then underwent an error-checking procedure and food nutrients calculated using the above database which is capable of a breakdown of foods into eighty-four different nutrients.

\section{Statistical methods}

The usual measures of the 'average' value and variation in a set of results are the (arithmetic) mean and the standard deviation. In the present study the distributions of the nutrients are skewed to the right and some of the derived percentages are also skewed to the right, though to a lesser degree. In addition there is the problem of under- and overreporting (see discussion). Accordingly, since the mean and particularly the standard deviation are affected by these two factors, the median is used as representative of a set of results and the 25 th and 75 th percentiles as a measure of variation. These ranking measures seem appropriate if the assumptions are made that the 'true' intake of an over- (under-) reporter is relatively high (low) compared with other subjects in the group. The choice of the 25 th and 75 th percentiles rather than say the 10 th and 90 th percentiles is motivated by the percentages of over- and under-reporters (see discussion). The corresponding mean values for the nutrients in Table 1 are of the order of $5 \%$ greater than the calculated medians; for Table 2, means and medians are similar. Statistical comparisons between subject age-sex groups were based on the Kolmogorov-Smirnov two-sample test at a $5 \%$ significance level.

\section{RESULTS}

Estimates of daily intake of energy, energy-yielding nutrients and dietary fibre in Northern Ireland adolescents are given in Table 1. As expected, energy intake (EI) was higher $(P<$ 0.001 ) in the 15-year-old boys compared with the 12-year-old boys. The EI of girls was similar in both groups and was significantly $(P<0.001)$ lower than for boys. The EI: basal metabolic rate (BMR) ratio was significantly lower $(P<0.001)$ for the 15 -year-old girls compared with the other groups.

Girls did not show any significant age-related differences in intakes of nutrients (Table 1). The older boys had significantly higher intakes of all nutrients $(P<0.001)$ than the younger boys. There were no differences, however, between the two groups of boys when intakes of protein, carbohydrate, total sugars, total fat, saturated fatty acids (SFA) and monounsaturated fatty acids (MUFA) and polyunsaturated fatty acids (PUFA) were expressed as a percentage of total energy contribution from energy-yielding nutrient intake (Table 2). As might be expected from the differences in EI, boys had significantly higher intakes of nutrients except for PUFA and dietary fibre (Table 1) than girls. However, when nutrient intakes were compared as percentages of total energy intake (Table 2) the only important differences were total sugars (12-year-old girls $>15$-year-old boys, $P<0.01$ ) and PUFA (15-year-old girls $>$ boys, $P<0.001 ; 12$-year-old girls $>12$-year-old boys, $P<$ $0 \cdot 001)$.

These qualitative differences in fat intakes were reflected in significantly higher PUFA:SFA (P:S) ratios (Table 1) in the diets of 12-year-old girls compared with 12-yearold boys $(P<0.01)$ and the diets of 15 -year-old girls compared with boys $(P<0.01)$. While 
Table 1. Median daily intake of energy-yielding nutrients and dietary fibre in Northern Ireland adolescents*

(Median values with 25 th and 75 th percentiles given in parentheses)

\begin{tabular}{|c|c|c|c|c|}
\hline \multirow[b]{3}{*}{ Energy (MJ) } & \multicolumn{2}{|c|}{ Boys } & \multicolumn{2}{|c|}{ Girls } \\
\hline & 12 years $(n 251)$ & 15 years $(n 252)$ & 12 years $(n 258)$ & 15 years $(n 254)$ \\
\hline & $11.0(9 \cdot 1,13.8)$ & $13 \cdot 1 \quad(11 \cdot 4,15 \cdot 3)$ & $9 \cdot 2(7 \cdot 8,11 \cdot 0)$ & $9 \cdot 1 \quad(7 \cdot 6,10 \cdot 9)$ \\
\hline $\mathrm{EI}: \mathbf{B M R} \uparrow$ & $1.9(1.6,2.3)$ & $1 \cdot 8 \quad(1 \cdot 6,2 \cdot 2)$ & $1.8(1.4,2 \cdot 1)$ & $1.5 \quad(1.3,1.9)$ \\
\hline Protein $(\mathrm{g})$ & $72 \quad(61,86)$ & $87 \quad(71,106)$ & $60 \quad(50,71)$ & $60 \quad(50,72)$ \\
\hline Carbohydrate (g) & $(287,438)$ & $(339,471)$ & $(242,346)$ & $(234,337)$ \\
\hline Sugars (g) & $139 \quad(112,185)$ & $162 \quad(131,203)$ & $121 \quad(97,150)$ & $118 \quad(89,150)$ \\
\hline Dietary fibre (g) & $20 \cdot 0 \quad(16 \cdot 2,25 \cdot 3)$ & $23 \cdot 8 \quad(18 \cdot 8,29 \cdot 0)$ & $17.9(14.9,22.0)$ & $19 \cdot 1 \quad(14 \cdot 6,23 \cdot 4)$ \\
\hline Fat (g) & $112(90,143)$ & $135 \quad(110,160)$ & $94 \quad(76,116)$ & $93 \quad(79,115)$ \\
\hline SFA (g) & $45 \cdot 6(35 \cdot 9,59 \cdot 3)$ & $54.0 \quad(43.5,66.9)$ & $36 \cdot 3(28 \cdot 4,46 \cdot 7)$ & $36.4 \quad(28.8,45-7)$ \\
\hline MUFA (g) & $36 \cdot 8 \quad(28 \cdot 7,47 \cdot 1)$ & $43 \cdot 7 \quad(35 \cdot 6,52 \cdot 8)$ & $30 \cdot 0 \quad(24 \cdot 2,37 \cdot 2)$ & $30.3 \quad(24.8,38.0)$ \\
\hline PUFA (g) & $15 \cdot 4(11 \cdot 6,20 \cdot 2)$ & $19 \cdot 2(14 \cdot 5,25 \cdot 0)$ & $14 \cdot 5(10 \cdot 7,19 \cdot 1)$ & $14.9(11.5,19.2)$ \\
\hline $\mathrm{P}: \mathrm{S}$ ratio & $0.33(0.24,0.47)$ & $0.36(0.27,0.50)$ & $0.39(0.29,0.54)$ & $0.42(0.30,0.54)$ \\
\hline
\end{tabular}

EI, energy intake; BMR, basal metabolic rate; SFA, saturated fatty acids; MUFA, monounsaturated fatty acids; PUFA, polyunsaturated fatty acids; $P: S$ ratio, polyunsaturated to saturated fatty acid ratio.

* For details of subjects and procedures, see pp. 344-345.

$\dagger$ Ratio of daily energy intake to predicted BMR.

Table 2. Median percentage of total energy intake contributed by energy-yielding nutrients in Northern Ireland adolescents*

(Median values with 25 th and 75 th percentiles given in parentheses)

\begin{tabular}{|c|c|c|c|c|}
\hline \multirow[b]{3}{*}{ Protein } & \multicolumn{2}{|c|}{ Boys } & \multicolumn{2}{|c|}{ Girls } \\
\hline & 12 years $(n 251)$ & 15 years $(n 252)$ & 12 years $(n 258)$ & 15 years $(n 254)$ \\
\hline & $11(10,12)$ & $(10,12)$ & $11 \quad(10,12)$ & $11 \quad(10,12)$ \\
\hline Carbohydrate & $50 \quad(47,53)$ & $50 \quad(47,53)$ & $50 \quad(47,54)$ & $49 \quad(46,51)$ \\
\hline Sugars & $20 \quad(17,23)$ & $20 \quad(16,24)$ & $21 \quad(18,24)$ & $20 \quad(17,24)$ \\
\hline Fat & $39 \quad(36,42)$ & $(36,41)$ & $(36,42)$ & $39 \quad(37,42)$ \\
\hline SFA & $16(14,18)$ & $(14,17)$ & $15 \quad(13,17)$ & $15 \quad(13,17)$ \\
\hline MUFA & $13(11,14)$ & $13(11,14)$ & $12(11,14)$ & $12(11,14)$ \\
\hline PUFA & $5 \cdot 2(4 \cdot 2,6 \cdot 4)$ & $5.5(4.6,7 \cdot 0)$ & $5 \cdot 9(4 \cdot 7,7 \cdot 3)$ & $6 \cdot 3(4 \cdot 9,7 \cdot 7)$ \\
\hline$n-3$ & $1 \cdot 3(1 \cdot 1,1 \cdot 7)$ & $1 \cdot 3(1 \cdot 0,1 \cdot 7)$ & $1.4(1 \cdot 1,1 \cdot 7)$ & $1.4(1.0,1.7)$ \\
\hline$n-6$ & $2 \cdot 5(2 \cdot 0,3 \cdot 8)$ & $2 \cdot 6(2 \cdot 1,4 \cdot 2)$ & $2 \cdot 9(2 \cdot 2,4 \cdot 5)$ & $3 \cdot 3(2 \cdot 4,5 \cdot 1)$ \\
\hline
\end{tabular}

SFA, saturated fatty acids; MUFA, monounsaturated fatty acids; PUFA, polyunsaturated fatty acids; $n-3$, total PUFA from $n-3$ family; $n-6$, total PUFA from $n-6$ family.

* For details of subjects and procedures, see pp. 344-345.

$n$-3 PUFA intakes were similarly low (1.3-1.4\% of total energy intake) in all of the sex-age groups, $n$-6 PUFA were significantly higher in 15 -year-old girls $(P<0$-001) compared with both groups of boys and in 12-year-old girls $(P<0.01)$ compared with 12-year-old boys (Table 2).

Only twelve boys and three girls in the younger age group reported drinking alcohol; the corresponding numbers were $78(31 \%)$ and $52(20 \%)$ for the 15-year-old boys and girls respectively. The median daily intakes of $\mathrm{Ca}$ and $\mathrm{Mg}$ are reported in Table 3. Girls did not 
Table 3. Median daily intake of calcium and magnesium in Northern Ireland adolescents (Median values with 25th and 75th percentiles given in parentheses)

\begin{tabular}{llllll}
\hline \hline & \multicolumn{2}{c}{ Boys } & \multicolumn{2}{c}{ Girls } \\
\cline { 2 - 3 } \cline { 5 - 6 } & 12 years $(n 251)$ & 15 years $(n 252)$ & & 12 years $(n$ 258) & 15 years $(n 254)$ \\
\hline $\mathrm{Ca}(\mathrm{g})$ & $1.03(0.79,1.28)$ & $1.18(0.96,1.53)$ & & $0.83(0.66,1.03)$ & $0.79(0.61,0.99)$ \\
$\mathrm{Mg}(\mathrm{g})$ & $0.29(0.24,0.37)$ & $0.36(0.29,0.42)$ & & $0.25(0.21, v .31)$ & $0.26(0.21,0.31)$ \\
\hline
\end{tabular}

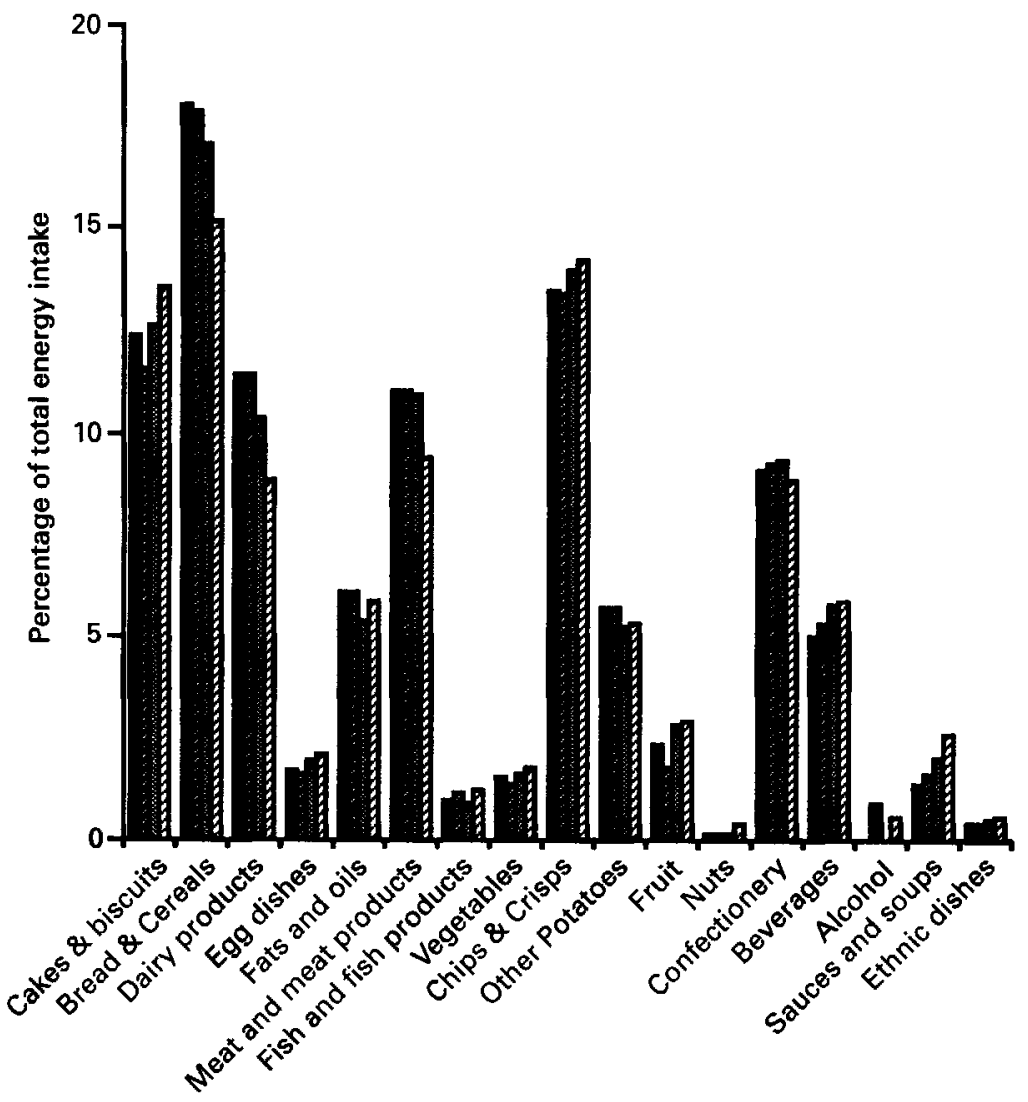

Fig. 1. Food sources of energy as a percentage of total energy intake in Northern Ireland adolescents. $\mathbf{\square}, 12$-yearold boys $(n 251) ; \boldsymbol{Z}, 15$-year-old boys $(n 252) ;$, 0 , 12-year-old girls $(n 258) ; \mathbb{Z}, 15$-year-old girls $(n 254)$.

show any significant age-related differences in $\mathrm{Ca}$ or $\mathrm{Mg}$ intakes but $\mathrm{Ca}$ and $\mathrm{Mg}$ intakes of girls were significantly $(P<0.001)$ lower than those of boys. The older boys had significantly $(P<0.001)$ higher $\mathrm{Ca}$ and $\mathrm{Mg}$ intakes than the younger boys.

Fig. 1 gives the food sources of energy. Bread and cereals contributed about $15-18 \%$ of total energy intake while cakes and biscuits (12-14\%), chips and crisps (13-14\%), dairy products $(9-11 \%)$, meat and meat products (9-11\%) and confectionery $(9 \%)$ were also substantial food sources of energy. 


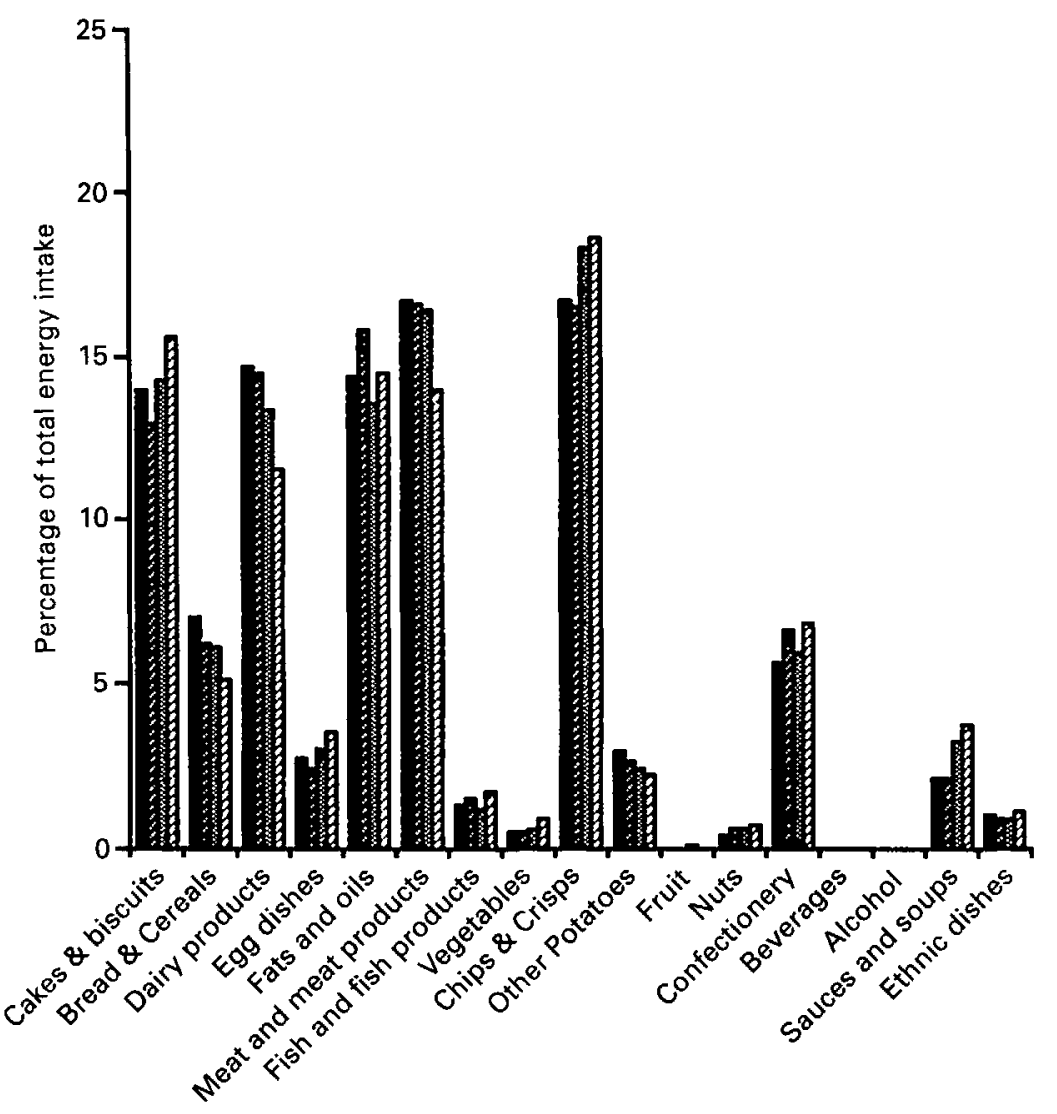

Fig. 2. Food sources of fat as a percentage of total fat intake in Northern Ireland adolescents. $\mathbf{\square}, 12$-year-old boys ( $n$ 251); $\boldsymbol{Z}, 15$-year-old boys $(n 252)$; 图, 12-year-old girls $(n 258) ; \square, 15$-year-old girls $(n 254)$.

The food sources of fat are given in Fig. 2. The food grouping chips and crisps (16-19\% of total fat intakes) was a major source of fat, especially in the older age group, while the groupings meat and meat products, fats and oils, cakes and biscuits, and dairy products each contributed about $15 \%$ of total fat intakes.

\section{DISCUSSION}

Recent studies (Livingstone et al. 1990, 1992) have demonstrated major discrepancies between EI observed in free-living adults and adolescents and energy expenditure either measured using doubly-labelled water or estimated from expected energy requirements based on multiples of BMR (physical activity level; PAL: James et al. 1988). Mean daily, EI assessed by this diet history method have been found to be in closer agreement with energy expenditure (when independently validated using doubly-labelled water as a measure of energy expenditure) than those obtained by weighed dietary record in a sample of boys and girls aged 12 and 15 years from similar population groups (Livingstone $e t$ al. 1992). Nevertheless, the diet history method is prone to both under- and over-reporting at the individual level. In the present study the estimate of a subject's daily habitual food intake was considered to be unrealistic if his or her EI:BMR ratio (predicted by the method of Schofield et al. 1985) was less than 1.14 (under-reporting) or greater than 2.5 (over- 
reporting). Thus data for a subject whose ratio lies outside this range are of doubtful validity.

A recent evaluation of EI data using fundamental principles of energy physiology found that $68 \%$ of the dietary surveys examined had mean EI:BMR values below the study specific cut-off value (Black et al. 1991). A serious bias towards under-reporting was not apparent in the current study where the EI:BMR value for each sex-age group was above the cut-off value of 1.52 for a study of this size using the diet history methodology (Black et al. 1991). Nevertheless the values of EI:BMR in this study ranged from 0.6 to 5.4 indicating that there were reported intakes which were highly unlikely to be representative of actual food intakes. Thus a statistically-derived (Goldberg et al. 1991) lower cut-off value for EI:BMR of an individual was set at 1.14 and records falling below this level were considered to be under-reported. The upper cut-off value of EI:BMR was set at $2 \cdot 5$. This was derived rather more arbitrarily based on hypothetical factorial calculations of typical energy expenditures and the total energy expenditure:BMR ratios of 12- and 15-year-old adolescents in Northern Ireland obtained by the use of doubly-labelled water (Livingstone et al. 1992). When these cut-off points were employed to classify subjects into underreporters and over-reporters and those whose records could be indicative of actual food intake, a total of $21.5 \%$ of 12 -year-old boys and $13.5 \%$ of 15 -year-old boys were classified as over-reporters in contrast to $8.9 \%$ and $5.1 \%$ of girls aged 12 and 15 years respectively. The 15-year-old girls were more likely to under-report $(13.4 \%)$ compared with 12-year-old girls $(7.8 \%), 12$-year-old boys $(6.0 \%)$ and 15 -year-old boys $(5 \cdot 6 \%)$.

The use of cut-off values based on PAL, however, is still a matter of debate (Black et al. 1991). In dietary surveys such as the present one in which there is evidence of overreporting, it is difficult to derive an objective upper cut-off value. Also, having chosen cutoff values and hence classified the subjects, how should this classification be used in the analysis of the data? Elimination of subjects with doubtful food intakes would substantially reduce the number of subjects studied (by between 17 and $27 \%$ ) and, more importantly, would introduce difficulties in making inferences about the study population from the remainder of the random sample. Modification of the data from under- and over-reporters would be attractive; however, discovering an acceptable form of modification may prove to be very difficult since it is likely to be age- and sex-dependent. The third option is to retain all the data and use statistical methods which are robust to values in the tails of the distributions of the nutrients being studied, e.g. to use percentiles as in the current study.

The median EI of each sex-age group was considerably higher than the corresponding estimated average requirements (EAR) for energy (9.27 and $11.51 \mathrm{MJ} / \mathrm{d}$ for boys, and 7.92 and $8.83 \mathrm{MJ} / \mathrm{d}$ for girls aged $11-14$ years and $15-18$ years respectively) published recently for the UK (Department of Health, 1991). The EAR values were based (in part) on calculations of energy expenditure for boys weighing 39 and $57 \mathrm{~kg}$ and girls weighing 41 and $53 \mathrm{~kg}$ aged 12.5 and 15.5 years respectively. Mean weights of adolescents of these ages in Northern Ireland (Boreham et al. 1993) were 43 (SD 9.4) and 59 (SD 9.4) $\mathrm{kg}$ for boys and 44 (SD 9.0) and 57 (SD 8.5) for girls aged 12 and 15 years respectively (corresponding mean heights $(\mathrm{m})$ were 1.50 (SD 0.08), 1.69 (SD 0.07), 1.51 (SD 0.07) and 1.61 (SD 0.06) respectively). Thus average energy requirements of these adolescents would be expected to be higher than the EAR. Nevertheless the median EI of these sex-age groups in Northern Ireland would suggest either much higher physical activity levels or inappropriately high EI values compared with the reference counterparts (Department of Health, 1991). The former possibility was not supported by the percentage of this population deemed to have low physical activity by questionnaire $(24-31 \%)$ while $18-34 \%$ were classified as having excessive body fat (Boreham et al. 1993). The EI of the Northern Ireland 12-year-olds were much higher than those measured by two $3 \mathrm{~d}$ dietary records reported for 11-12-year-old 
Northumbrian children (Adamson et al. 1992b). Average EI of Northumbrian children of this age-group appeared to fall over the period 1980 to 1990 even though there was a concomitant increase in height and weight.

Food sources of dietary energy demonstrated the importance of bread and cereals, cakes and biscuits, and chips and crisps groupings for each sex and age. Energy derived from meat and meat products at around $10 \%$ of total energy intake was considerably below the value (15.5\%) reported for young adolescent English children (Adamson et al. 1992a). Mean vegetable intakes at 75 and $83 \mathrm{~g} / \mathrm{d}$ for boys aged 12 and 15 years respectively and 73 and $80 \mathrm{~g} / \mathrm{d}$ for girls of these ages were substantially lower than those reported by 14-16year-olds in France (Boggio \& Klepping, 1981), by 11-14-year-olds in the Portuguese National Food Consumption Survey and by 10-15-year-olds in the National Nutrition Survey of the Netherlands (see Nutriscan, 1993). Vegetable consumption, however, was similar to intakes reported in the Irish National Nutrition Survey (Lee \& Cunningham, 1990) for adolescents of these age groups. Mean fruit intakes were 126 and $114 \mathrm{~g} / \mathrm{d}$ for boys aged 12 and 15 years respectively and 135 and $142 \mathrm{~g} / \mathrm{d}$ for girls of these ages. Although these intakes were slightly lower than those reported for Portuguese (see Nutriscan, 1993) and French (Boggio \& Klepping, 1981) adolescents, they were similar to fruit intakes reported by adolescents in the Netherlands (see Nutriscan, 1993) and Ireland (Lee \& Cunningham, 1990).

Median intake of protein was appreciably above the reference nutrient intake (RNI) for each sex-age group (Department of Health, 1991) although intakes were only $11 \%$ of EI. Average carbohydrate intake was $49 \%$ of EI while average dietary fibre intakes were the same as other adolescent groups in Finland (Räsänen et al. 1991) and New Zealand (Tan et al. 1989).

Fat as a percentage of EI for this population was about $39 \%$ which is considerably above the dietary reference value (DRV) for the UK (Department of Health, 1991). Intakes were similar to adult intakes of fat estimated in 1986/1987 in this population by $7 \mathrm{~d}$ weighed dietary records (Strain et al. 1990). These levels of total fat intake were also similar to those estimated for Finnish (Räsänen et al. 1991) and New Zealand (Tan et al. 1989) adolescents but above those estimated for British (Department of Health, 1989), Dutch (Van Poppel et al. 1991), French (Michaud et al. 1991) and Irish (Lee \& Cunningham, 1990) counterparts of the same age using various dietary intake methodologies. Although the possible relationship between high fat intake and the development of obesity is currently a subject of debate (Leibel, 1992), low-fat diets have been shown to be valuable in the management of established obesity (Royal College of Physicians, 1983). Thus, a lowering of fat intake by this population may reduce the presently high level of obesity (Boreham et al. 1993). Major contributors to total fat intake of this population were the food groupings chips and crisps, meat and meat products, fats and oils, cakes and biscuits and dairy products.

The SFA intake of about $15 \%$ for this population was also above the DRV (10\%) for the UK adult population. Girls consumed less SFA than boys and the SFA intakes of both sexes were below those of Finnish (Räsänen et al. 1991) and New Zealand (Tan et al. 1989) adolescents.

The MUFA intakes ( $13 \%$ of EI) of the Northern Ireland adolescents were below average intakes of MUFA of $20 \%$ of EI in some Mediterranean populations (Ferro-Luzzi \& Sette, 1989). There is currently much interest in the health-promoting properties of what is known as a 'Mediterranean diet' which is characterized inter alia by relatively high intakes of olive oil containing the MUFA oleic acid. There is now increasing evidence that oleic acid, when it replaces SFA in the diet, decreases both plasma total and low-density-lipoprotein (LDL)cholesterol (Foley et al. 1992). Nevertheless, MUFA intakes in this population are similar 
to those recommended for adults in the UK (Department of Health, 1991) and which currently reflect average adult intakes of MUFA in Great Britain (Gregory et al. 1990).

Total PUFA intakes at $5 \cdot 2$ and $5.5 \%$ of daily total energy intake of adolescent boys aged 12 and 15 years respectively in Northern Ireland were also less than the DRV of $6 \%$ of daily total energy intake for adults in the UK. The girls had higher intakes of PUFA and higher dietary $\mathbf{P}: \mathrm{S}$ ratios compared with boys. A recent report (British Nutrition Foundation, 1992) recommended that the $P: S$ ratio should no longer be used. Reasons given were that there were differences among SFA in their plasma cholesterol-raising potential and that it did not recognize the possible role of MUFA in lowering LDLcholesterol nor the physiological differences in the $n-6$ and $n-3$ PUFA. The report also recommended increased intakes of $n-3$ PUFA by the general population. The recommended safe range of total $n$-3 PUFA intakes for healthy individuals was between 0.5 and $4.5 \%$ of total energy intake. Average intakes of $n-3$ PUFA by Northern Ireland adolescents were in the lower part of this recommended intake range.

Median $\mathrm{Ca}$ and $\mathrm{Mg}$ intakes of this population were above the EAR for these minerals (Department of Health, 1991) of 0.75 and $0.625 \mathrm{~g} \mathrm{Ca} / \mathrm{d}$ for males and females respectively and 0.23 and $0.25 \mathrm{~g} \mathrm{Mg} / \mathrm{d}$ for 12-year-olds and 15-year-olds respectively.

In conclusion, protein, carbohydrate and fat intakes as a percentage of total energy intake of Northern Ireland adolescents varied little between the sexes or between the 12year-olds and 15-year-olds. Dietary fat and SFA intakes were high by national and international standards while intakes of fruit and especially vegetables were low compared with some other European populations. Based on these results, concern about the dietary habits and related health consequences in Northern Ireland adolescents appears justified.

This study was supported by the Northern Ireland Chest, Heart and Stroke Association and the Department of Health and Social Services (Northern Ireland).

\section{REFERENCES}

Adamson, A., Rugg-Gunn, A. J., Appleton, D. R., Butler, T. J. \& Hackett, A. F. (1992a). Dietary sources of energy, protein, unavailable carbohydrate and fat in 11-12-year old English children in 1990 compared with results in 1980. Journal of Human Nutrition and Dietetics 5, 371-385.

Adamson, A., Rugg-Gunn, A., Butler, T., Appleton, D. \& Hackett, A. (1992b). Nutritional intake, height and weight of 11-12-year-old Northumbrian children in 1990 compared with information obtained in 1980. British Journal of Nutrition 68, 543-563.

Black, A. E., Goldberg, G. R., Jebb, S. A., Livingstone, M. B. E., Cole, T. J. \& Prentice, A. M. (1991). Critical evaluation of energy intake data using fundamental principles of energy physiology. 2. Evaluating the results of published surveys. European Journal of Clinical Nutrition 45, 583-599.

Boggio, V. \& Klepping, J. (1981). Characteristiques de la ration alimentaire de l'enfant (Characteristics of infant diets). Archives of French Paediatrics 38, 678-686.

Boreham, C., Savage, M., Primrose, D., Cran, G. \& Strain, J. J. (1993). Coronary risk factors in schoolchildren. Archives of Disease in Childhood 68, 182-186.

British Nutrition Foundation (1992). Unsaturated Fatty Acids: Nutritional and Physiological Significance. The Report of the British Nutrition Foundation's Task Force. London: Chapman \& Hall.

Crawley, H. (1988). Food Portion Sizes. London: H.M. Stationery Office.

Department of Health (1989). The Diets of British Schoolchildren. Report on Health and Social Subjects no. 36. London: H.M. Stationery Office.

Department of Health (1991). Dietary Reference Values for Food Energy and Nutrients for the United Kingdom. Report on Health and Social Subjects no. 41. London: H.M. Stationery Office.

Ferro-Luzzi, A. \& Sette, S. (1989). The Mediterranean diet: an attempt to define its present and past composition. European Journal of Clinical Nutrition 43 (Suppl), 13-29.

Foley, M., Ball, M., Chisholm, A., Duncan, A., Spears, G. \& Mann, J. (1992). Should mono- or poly-unsaturated fats replace saturated fat in the diet? European Journal of Clinical Nutrition 46, 429-436.

Goldberg, G. R., Black, A. E., Jebb, S. A., Cole, T. J., Murgatroyd, P. R., Coward, W. A. \& Prentice, A. M. (1991). Critical evaluation of energy intake data using fundamental principles of energy physiology. 1. Derivation of cut-off limits to identify under-recording. European Journal of Clinical Nutrition 45, 569-581. 
Gregory, J., Foster, K., Tyler, H. \& Wiseman, M. (1990). The Dietary and Nutritional Survey of British Adults. London: H.M. Stationery Office.

James, W. P. T., Ferro-Luzzi, A. \& Waterlow, J. C. (1988). Definition of chronic energy deficiency in adults. Report of a working party of the International Dietary Energy Consultancy Group. European Journal of Clinical Nutrition 42, 969-981.

Lee, P. \& Cunningham, K. (1990). Irish National Nutrition Survey. Dublin: The Irish Nutritional and Dietetic Institute.

Leibel, R. L. (1992). Fat as fuel and metabolic signal. Nutrition Reviews 50, $12-16$.

Livingstone, M. B. E., Prentice, A. M., Coward, W. A., Strain, J. J., Black, A. E., Davies, P. S. W., Stewart, C. M., McKenna, P. G. \& Whitehead, R. G. (1992). Validation of estimates of energy intake by weighed dietary record and diet history in children and adolescents. American Journal of Clinical Nutrition 56, 29-35.

Livingstone, M. B. E., Prentice, A. M., Strain, J. J., Coward, W. A., Black, A. E., Barker, M. E., McKenna, P. G. \& Whitehead, R. G. (1990). Accuracy of weighed dietary records in studies of diet and health. British Medical Journal 300, 708-712.

McClean, R., McCrum, E., Scally, G., McMaster, D., Patterson, C., Jackson, N. \& Evans, A. (1990). Dietary patterns in the Belfast MONICA Project. Proceedings of the Nutrition Society 49, 497-305.

Michaud, C., Comiglion, J. M., Michel, F., Musse, N., Nicolas, J. P. \& Mejean, L. (1991). Sources of macronutrients and energy in the diet of a group of French high-school students on school-days. Journal of Human Nutrition and Dietetics 4, 91-99.

Nutriscan (1993). Nutrifile - A Food and Nutrition Atlas of the European Community. Dublin: Nutriscan Limited.

Paul, A. A. \& Southgate, D. A. T. (1978). McCance and Widdowson's The Composition of Foods, 4th ed. London: H.M. Stationery Office.

Paul, A. A., Southgate, D. A. T. \& Russell, J. (1980). First Supplement to McCance and Widdowson's The Composition of Foods. London: H.M. Stationery Office.

Prasad, C. \& Chandra, R. K. (1991). Atherosclerosis: a pediatric problem? (Editorial) Nutrition Research 11, 1-3.

Räsänen, L., Laitinen, S., Stirkkinen, R., Kimppa, S., Viikari, J., Uhari, M., Pesonen, E., Salo, M. \& Akerblom, H. K. (1991). Composition of the diet of young Finns in 1986. Annals of Medicine 23, 73-80.

Royal College of Physicians (1983). Obesity: a report of the Royal College of Physicians. Journal of the Royal College of Physicians 17, 3-58.

Schofield, W. N., Schofield, C. \& James, W. P. T. (1985). Basal metabolic rate. Human Nutrition: Clinical Nutrition 39C (Suppl. 1), 11-96.

Strain, J. J., Barker, M. E., Livingstone, M. B. E. \& McKenna, P. G. (1990). The Northern Ireland dietary survey and related studies. Proceedings of the Nutrition Society 49, 289-296.

Tan, S. P., Wells, J. E., Beaven, D. W. \& Hornblow, A. R. (1989). Energy and macronutrient intake of New Zealand adolescents. Ecology of Food and Nutrition 23, 225-236.

Uemura, K. \& Pisa, Z. (1988). Trends in cardiovascular disease mortality in industrial countries since 1950. World Health Statistical Quarterly 41, 155-178.

Van Poppel, G., Schneijder, P., Lowik, M. R. H., Schrijver, J. \& Kok, F. J. (1991). Nutritional status and food composition in 10-11 year old Dutch boys (Dutch Nutrition Surveillance System). British Journal of Nutrition 66, 161-169.

Van Stavern, W. A., de Boer, J. D. \& Burema, J. (1985). Validity and reproducibility of a dietary history method estimating the usual food intake during one month. American Journal of Clinical Nutrition 42, 554-559. 